\title{
Systemically administered allogeneic mesenchymal stem cells do not aggravate the progression of precancerous lesions: a new biosafety insight
}

\author{
Flavia Bruna ${ }^{1,2}$, Anita Plaza ${ }^{1,3}$, Martha Arango ${ }^{1,4}$, Iris Espinoza ${ }^{1}$ and Paulette Conget ${ }^{1 *}$ (1)
}

\begin{abstract}
Background: Mesenchymal stem cells (MSCs) are a heterogeneous subset of stromal cells currently tested for multiple therapeutic purposes. Their potential to home into tumors, to secrete trophic/vasculogenic factors, and to suppress immune response raises questions regarding their biosafety. Our aim was to evaluate whether systemically administered allogeneic MSCs modify the natural progression of precancerous lesions and whether their putative effect depends on cancer stage and/or cell dose.

Methods: Oral squamous cell carcinoma (OSCC) was induced in Syrian golden hamsters by topical application of 7,12-dimethylbenz[a]anthracene in one buccal pouch. At hyperplasia, dysplasia, or papilloma stage, animals received intracardially the vehicle or $0.7 \times 10^{6}, 7 \times 10^{6}$, or $21 \times 10^{6}$ allogeneic bone marrow-derived MSCs $/ \mathrm{kg}$. OSCC progression was assessed according to the presence of erythroplakia and leukoplakia, extent of inflammation and vascularization, and appearance, volume, and staging of tumors. Also, the homing of donor cells was studied.

Results: Precancerous lesions progressed from hyperplasia to dysplasia in 2 weeks, from dysplasia to papilloma in 3 weeks, and from papilloma to carcinoma in 4 weeks. This time course was unmodified by the systemic administration of MSCs at hyperplasia or dysplasia stages. When MSCs were administered at papilloma stage, lesions did not progress to carcinoma stage. Tumors developed in hamsters receiving $0.7 \times 10^{6}$ or $7 \times 10^{6} \mathrm{MSCs} / \mathrm{kg}$ at hyperplasia stage were significantly smaller than those found in control animals $\left(25 \pm 4\right.$ or $23 \pm 4 \mathrm{~mm}^{3}$ versus $72 \pm 19 \mathrm{~mm}^{3}, p<0.05$ ). Similar results were obtained when $0.7 \times 10^{6}, 7 \times 10^{6}$, or $21 \times 10^{6} \mathrm{MSCs} / \mathrm{kg}$ were administered at papilloma stage $\left(44 \pm 15,28 \pm 7\right.$, or $28 \pm 5 \mathrm{~mm}^{3}$ versus $\left.104 \pm 26 \mathrm{~mm}^{3}, p<0.05\right)$. For dysplasia stage, only the lower concentration of MSCs reached statistical significance ( $21 \pm 9 \mathrm{~mm}^{3}$ versus $\left.94 \pm 39 \mathrm{~mm}^{3}, p<0.05\right)$. Animals receiving $21 \times 10^{6} \mathrm{MSCs} / \mathrm{kg}$ at hyperplasia stage developed tumors larger than those found in animals that received the vehicle $\left(147 \pm 47 \mathrm{~mm}^{3}\right.$ versus $\left.72 \pm 19 \mathrm{~mm}^{3}, p<0.05\right)$. Donor cells were rarely found in precancerous lesions.
\end{abstract}

Conclusions: Systemically administered allogeneic MSCs do not aggravate the progression of precancerous lesions. Moreover, they preclude cancer progression and tumor growth.

Keywords: Mesenchymal stem cells, Multipotent stromal cells, Oral squamous cell carcinoma, Systemic administration, Cancer progression, Biosafety

\footnotetext{
* Correspondence: pconget@udd.cl

${ }^{1}$ Centro de Medicina Regenerativa, ICIM, Facultad de Medicina Clinica

Alemana Universidad del Desarrollo, Av. Las Condes 12,438, Lo Barnechea,

Santiago, Chile

Full list of author information is available at the end of the article
}

(c) The Author(s). 2018 Open Access This article is distributed under the terms of the Creative Commons Attribution 4.0 International License (http://creativecommons.org/licenses/by/4.0/), which permits unrestricted use, distribution, and reproduction in any medium, provided you give appropriate credit to the original author(s) and the source, provide a link to the Creative Commons license, and indicate if changes were made. The Creative Commons Public Domain Dedication waiver (http://creativecommons.org/publicdomain/zero/1.0/) applies to the data made available in this article, unless otherwise stated. 


\section{Background}

Mesenchymal stem cells (MSCs) are self-renewable undifferentiated cells found in almost all adult tissues [1]. MSCs can be procured from living donors, can be efficiently expanded ex vivo [2], are hypoimmunogenic so a conditioning regimen is not required before their transplantation [3], home into injured tissues and tumors $[4,5]$, differentiate into tissue cells [6], secrete trophic factors [7], promote neovascularization [8], reduce oxidative stress [9], and modulate the immune response [10]. Thus, MSCs appear to be an ideal tool for cell-based therapies.

The number of people receiving MSCs worldwide is increasing [11]. Some of them are patients enrolled in clinical trials but many of them receive the cells in the context of commercial unproved medical or cosmetic offers. Results of clinical trials are promising, nonetheless safety issues regarding MSC-based therapies are still unproven [12].

Currently, the envisioned adverse effects related to MSC administration are embolization, acute or chronic rejection, zoonosis when animal-derived products are used for cell expansion, increased susceptibility to infections, or upcoming neoplasia [13, 14]. A systematic review of 36 clinical trials showed no association between the intravascular administration of MSCs and acute toxicity, organ complications, infections, or de-novo malignancies [15]. Paradoxically, in animal models it has been shown that MSCs have both antitumor and protumor effects $[14,16]$. Discrepancies have been explained by the source, dose, or delivery route, and also by the type and stage of cancer.

In order to fulfill a conclusive safety profile of MSCs, large-scale controlled studies with longer follow-up of adverse events are indispensable. Together, novel biosafety concerns should be studied systematically. One of these is the impact of MSC administration on the progression of precancerous lesions. These lesions are underdiagnosed and precede skin, oral cavity, esophagus, lung, pancreas, bladder, gallbladder, breast, ovary, cervix, and prostate cancers [17].

The aim of our work was to evaluate whether systemically administered allogeneic MSCs modify the natural progression of precancerous lesions and whether their putative effect depends on cancer stage and/or cell dose. For this, we used a preclinical model of oral squamous cell carcinoma (OSCC) that reproduces the etiology, malignant features, and dynamics of human oral epithelial tumors [18, 19].

\section{Methods}

\section{Study design}

OSCC was induced in one buccal pouch of adult male hamsters. At hyperplasia, dysplasia, or papilloma stage, animals received intracardially the vehicle or $0.7 \times 10^{6}$,
$7 \times 10^{6}$, or $21 \times 10^{6}$ allogeneic bone marrow-derived MSCs/kg (Fig. 1). Every week, buccal pouches were assessed macroscopically. At the end of the study period (13 weeks), tumors were analyzed microscopically. For each stage, the homing of donor cells into precancerous lesions was evaluated 1 day after MSC administration.

The protocol was approved by the Ethic Committee of Facultad de Medicina Clinica Alemana-Universidad del Desarrollo (approval ID: 2011-14).

\section{Animals}

A total of 270 Syrian golden hamsters (Mesocricetus auratus) were used in this study: 90 served as MSC donors and 180 were OSCC induced (60 hyperplasia, 60 dysplasia, 60 papilloma). Animals were housed at $22{ }^{\circ} \mathrm{C}$, constant humidity, with a $12 \mathrm{~h}: 12 \mathrm{~h}$ light-dark cycle, and food and water ad libitum. Hamsters were anesthetized by intraperitoneal injection of $20 \mathrm{mg} / \mathrm{kg}$ xylazine (Centrovet, Chile) and $200 \mathrm{mg} / \mathrm{kg}$ ketamine (Ilium, Argentina), and were euthanized by intraperitoneal injection of $40 \mathrm{mg} / \mathrm{kg}$ xylazine and $400 \mathrm{mg} / \mathrm{kg}$ ketamine. To regulate respiratory frequency during anesthesia, animals received sublingually $0.2 \mathrm{mg}$ Viviram-V (Holliday Scott, Mexico).

\section{Induction of OSCC}

Healthy male hamsters, 8 weeks old, weighing $142 \pm 17 \mathrm{~g}$, were painted three times a week in their right buccal pouch with a No. 4 camel-hair brush soaked with $50 \mu$ of $0.5 \%(\mathrm{w} / \mathrm{v})$ dimethylbenz[a]anthracene (DMBA) (SigmaAldrich, St. Louis, MO, USA) dissolved in mineral oil (Sigma-Aldrich) [18].

Isolation, ex-vivo expansion, and characterization of MSCs Healthy female hamsters, 8 weeks old, were euthanized and femurs and tibias were procured under sterile conditions. The epiphyses were removed and bone marrow cells were collected by flushing bones with sterile phosphate buffer saline (Gibco, Auckland, New Zealand). Recovered cells were resuspended in alpha-MEM (Gibco) supplemented with $10 \%$ fetal bovine serum (Gibco) and $80 \mu \mathrm{g} / \mathrm{ml}$ gentamycin (Sanderson Laboratory, Chile), and plated at a density of $0.25 \times 10^{6}$ nucleated cells $/ \mathrm{cm}^{2}$ in plastic tissue-culture dishes. After $72 \mathrm{~h}$, nonadherent cells were removed by medium change. When foci reached confluence, adherent cells were detached with 0.25\% trypsin, $2.65 \mathrm{mM}$ EDTA (Gibco) and subcultured. At $70-80 \%$ confluence, cells were tripsinized, centrifuged, resuspended in alpha-MEM, counted, characterized, and injected.

Cell immunophenotyping was performed by flow cytometry after immunostaining with APC-conjugated antiCD45 (BD Pharmingen, USA), FITC-conjugated anti-alpha smooth muscle actin (Sigma), and FITC-conjugated mouse 


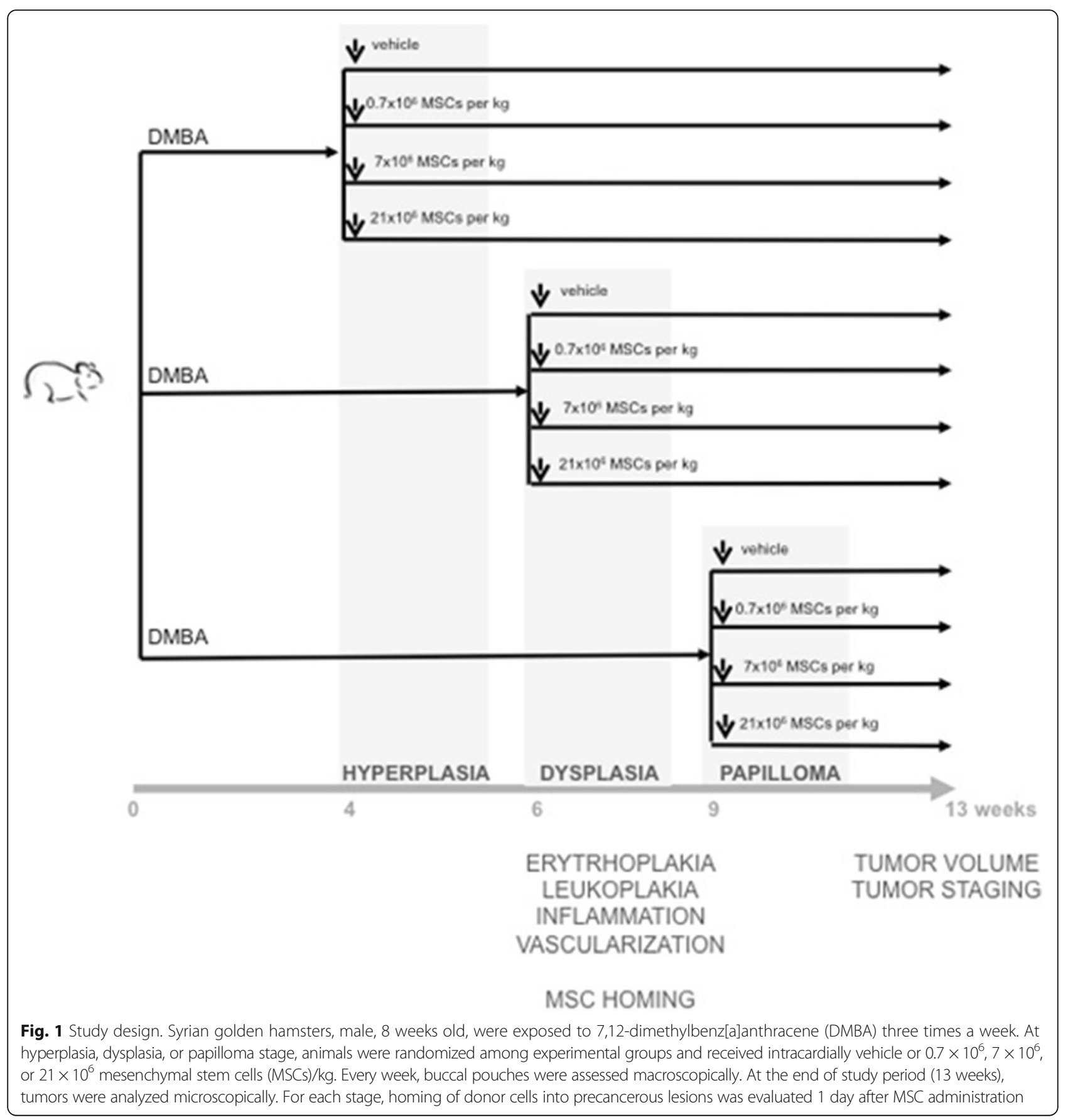

anti-vimentin (Oncogen, USA) [2]. To assess differentiation potentials, cells were incubated with adipogenic or osteogenic induction media [20]. Seven and 14 days later, samples were stained with Oil Red $\mathrm{O}$ or Alizarin Red (Sigma) (Additional file 1: Figure S1).

\section{Systemic administration of MSCs}

When the target OSCC stage was reached, animals were distributed randomly among the experimental groups. After anesthesia, the heart was palpated and the needle of a Tuberculin syringe (Terumo, Japan) was inserted at sternum height [21]. Once retrograde flow was observed, $600 \mu \mathrm{l}$ of $5 \%$ hamster plasma in physiological serum (vehicle) or $0.1 \times 10^{6}, 1 \times 10^{6}$, or $3 \times 10^{6}$ MSCs resuspended in the vehicle were injected. These numbers of cells results in doses of $0.7 \times 10^{6}, 7 \times 10^{6}$, or $21 \times 10^{6} \mathrm{MSCs} / \mathrm{kg}$, respectively.

\section{Macroscopic assessment of OSCC stages}

Four, 6, 9, and 13 weeks after the first DMBA exposure, animals were anesthetized and the right buccal pouch 
was exposed and photographed using a digital camera (FUJIFILM-Finepi HS20 EXR or Olympus SP5 10). Two independent observers analyzed the photographs and classified lesions according to the absence/presence of erythroplakia, leukoplakia, inflammation, vascularization, ulcers, or exophytic nodules [18]. Tumors were measured with a digital caliper (Mitutoyo Sul Americana, Brazil). The tumor volume was calculated using the formula: tumor volume $\left(\mathrm{mm}^{3}\right)=0.52 \times$ width $(\mathrm{mm})^{2} \times$ length $(\mathrm{mm})$ [22]

\section{Microscopic assessment of OSCC stages}

Thirteen weeks after the first DMBA exposure, animals were euthanized, right buccal pouches were procured, and tumors were resected. Samples were fixed in 10\% buffered formalin (Merck, USA), embedded in paraffin (Merck), and sectioned. Tissue sections of $4 \mu \mathrm{m}$ were deparaffinized with Neoclear (Merck), rehydrated with graded alcohols, stained with hematoxylin-eosin (Merck), and visualized with a light microscope (DM2000; Leica, Germany). Images were captured with a digital camera (DFC295; Leica). Samples were classified as hyperplasia, dysplasia, papilloma, or carcinoma as described previously $[18,19]$.

Histological analyses were performed blind by three independent observers; one of them is a pathologist expert in oral diseases.

\section{Detection of donor MSCs in recipient mucosa}

MSCs were labeled with $25 \mu \mathrm{M}$ CellTracker Red CMTPX (Invitrogen, USA) for $20 \mathrm{~min}$ at $37{ }^{\circ} \mathrm{C}$. After washing, cells were tripsinized and injected intracardially (see earlier). The day after, hamsters were euthanized, and buccal pouches were procured and fixed with OCT (Tissue-Teck, USA). Cryosections of $10 \mu \mathrm{m}$ thickness were stained with DAPI (Invitrogen, USA), mounted with epifluorescence medium (Dako, USA), and visualized with an epifluorescence microscope (DM2000 (Leica) or Flv10i.doc (Olympus, USA)) [6].

\section{Statistical analysis}

As data distribution was nonparametric, results were presented as median \pm SEM. Tumor volume comparisons were performed using one-way ANOVA test followed by Dunn's post test. Statistical analyses were performed using StatGraph Prism 5.0 software. $p<0.05$ with a confidence interval of $95 \%$ was considered statistically significant.

\section{Results}

Systemically administered allogeneic MSCs do not accelerate the progression of precancerous lesions Four weeks after the first DMBA exposure, buccal pouches of animals that received the vehicle were retracted, and erythroplakia, leukoplakia, or both were evident (Fig. 2). Together, an engrossment of the mucosa due to inflammation was observed. Two weeks later (6 weeks after the first DMBA exposure), mucosa engrossed and lost elasticity; no tumors were visible at this time point. Three weeks later ( 9 weeks after the first DMBA exposure), exophytic lesions protruded from the surface and therefore tumors were measurable. Four weeks later (13 weeks after the first DMBA exposure), buccal pouches retracted and stiffened, presenting features of necrosis and larger tumors. This time course was unchanged in animals receiving MSCs at hyperplasia (Fig. 2) or dysplasia (Fig. 3) stage. At week 13, the buccal pouches of animals receiving MSCs at papilloma stage neither retracted nor presented features of necrosis (Fig. 4). Also, tumors did not enlarge.

\section{Systemically administered allogeneic MSCs do not increase tumor malignancy}

Thirteen weeks after the first DMBA exposure, the oral mucosa of animals receiving the vehicle showed cell and nuclear pleomorphism, the epithelium stratification was lost, the basal membrane appeared discontinuous, vessels were aberrant (large size and discontinuous wall), and inflammatory foci were abundant (Figs. 5, 6, and 7). Therefore, at the end of the study period all animals receiving the vehicle presented carcinoma. The same was observed in hamsters receiving MSCs at hyperplasia stage (Fig. 5). For animals that received $0.7 \times 10^{6}, 7 \times 10^{6}$, or $21 \times 10^{6} \mathrm{MSCs} / \mathrm{kg}$ at dysplasia stage, the frequencies of lesions that progressed to carcinoma were 67, 66, and $90 \%$, respectively (Fig. 6). When MSC administration was performed at papilloma stage, the frequencies of malignant transformation were 27,13 , and $10 \%$ for $0.7 \times 10^{6}, 7 \times 10^{6}$, or $21 \times 10^{6} \mathrm{MSCs} / \mathrm{kg}$, respectively (Fig. 7). Most of the tumors found in animals receiving MSCs at papilloma stage remained at this stage, and showed continuous basal membrane and rare epithelial cells invading the stroma.

\section{Low doses of systemically administered allogeneic MSCs preclude OSCC tumor growth}

Thirteen weeks after the first DMBA exposure, the mean size of tumors developed in animals receiving the vehicle at hyperplasia, dysplasia, or papilloma stage was $90 \pm 28 \mathrm{~mm}^{3}$ (72 $\pm 19 \mathrm{~mm}, 94 \pm 39 \mathrm{~mm}$, and $104 \pm 26 \mathrm{~mm}$, respectively) (Fig. 8). The administration of $0.7 \times 10^{6}$ or $7 \times 10^{6} \mathrm{MSCs} / \mathrm{kg}$ at hyperplasia stage resulted in tumors three times smaller $\left(25 \pm 4 \mathrm{~mm}^{3}\right.$ or $\left.23 \pm 4 \mathrm{~mm}^{3}\right)$. However, the high dose of MSCs resulted in tumors two times bigger $\left(147 \pm 47 \mathrm{~mm}^{3}\right)$. All of the observed differences were statistically significant $(p<0.05)$ (Fig. 8). When MSCs were administered at dysplasia stage, no difference was observed when compared with the control, except for the low dose $\left(21 \pm 9 \mathrm{~mm}^{3}\right.$; $p<0.05)$. Animals that received MSCs at papilloma stage developed tumors two to three times smaller than those presented in control animals $\left(0.7 \times 10^{6} \mathrm{MSCs} / \mathrm{kg}\right.$, 

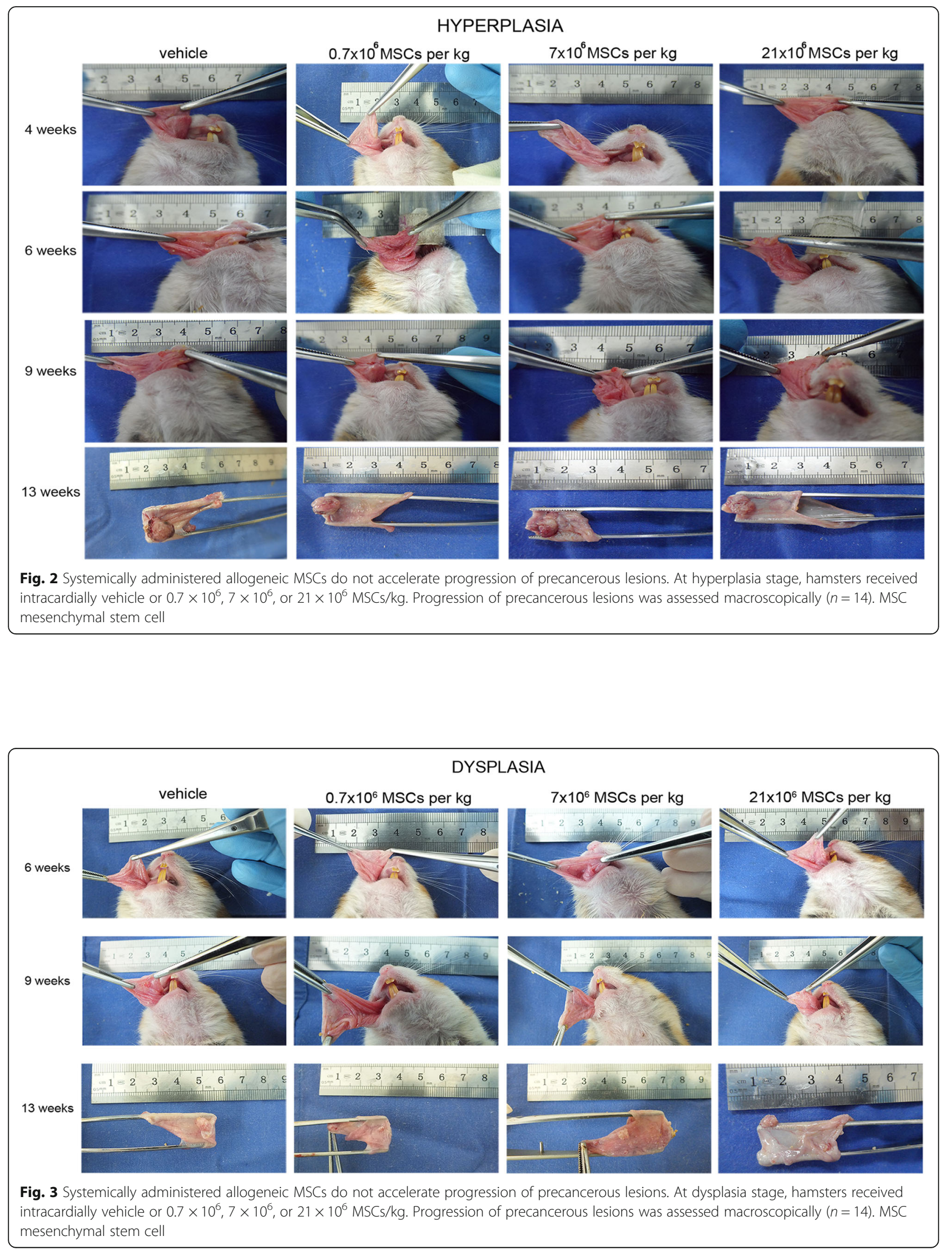

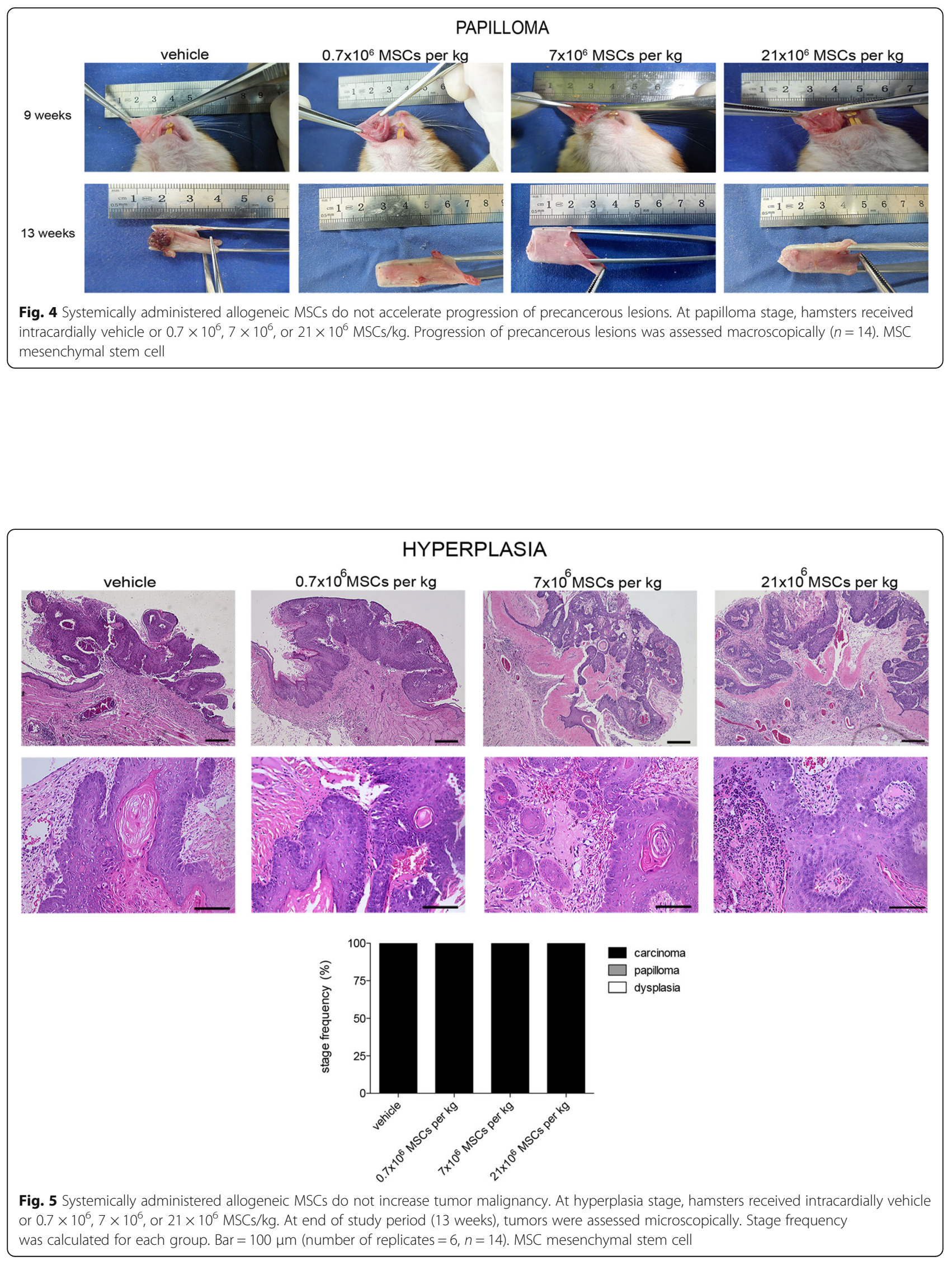


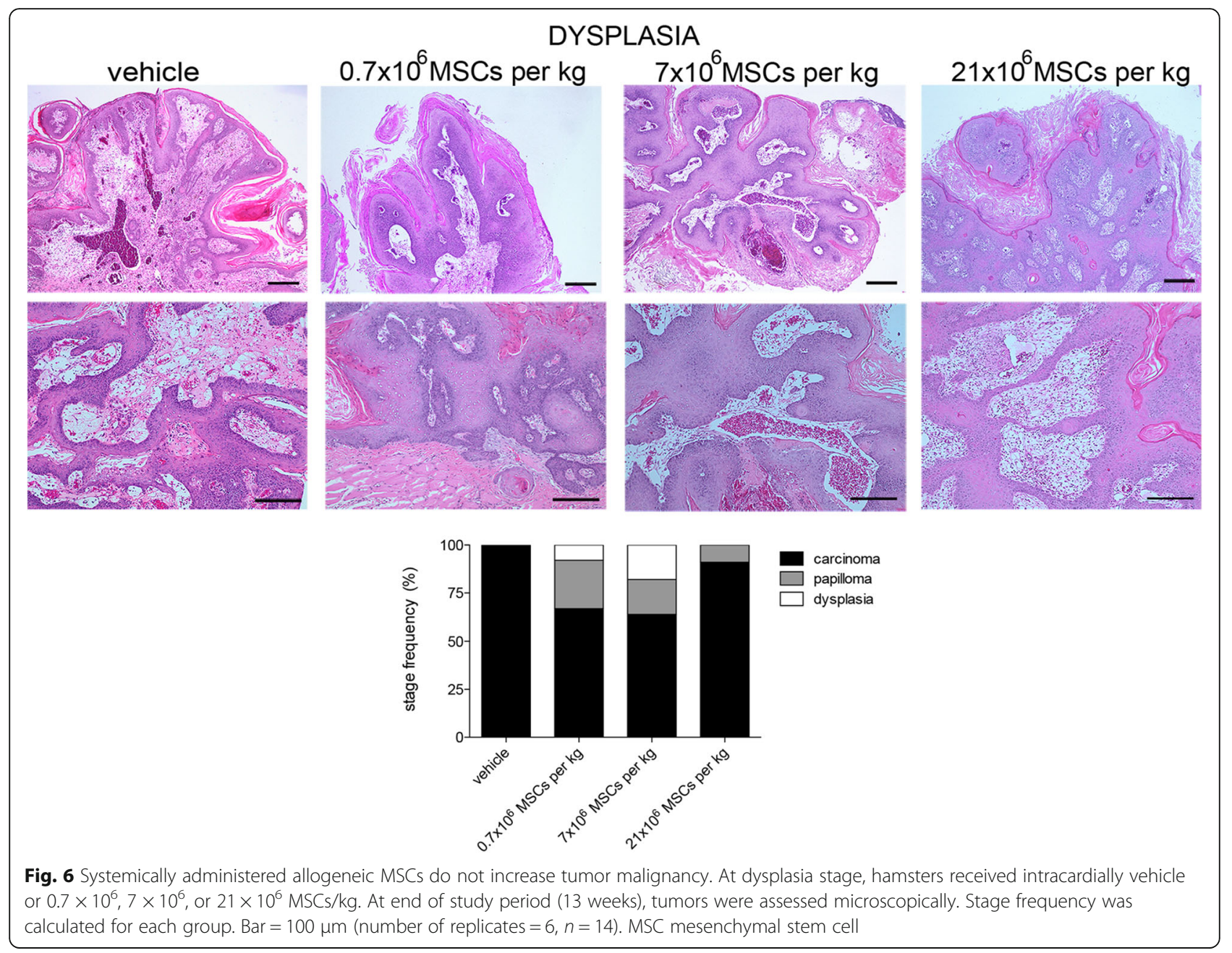

$44 \pm 15 \mathrm{~mm}^{3} ; 7 \times 10^{6} \mathrm{MSCs} / \mathrm{kg}, 28 \pm 7 \mathrm{~mm}^{3} ; 21 \times 10^{6}$ $\mathrm{MSCs} / \mathrm{kg}, 28 \pm 5 \mathrm{~mm}^{3} ; p<0.05$ for the three comparisons).

\section{Systemically administered allogeneic MSCs rarely home into precancerous lesions}

One day after intracardial administration, MSCs labeled with CMTPX (donor cells) were scarcely found in the oral mucosa of animals presenting precancerous lesions at dysplasia or papilloma stage, but not at hyperplasia stage (Fig. 9). Since not all of the sections analyzed presented donor cells and the number of donor was very low (1-3 cells/field), quantitative analysis was not performed.

\section{Discussion}

In this study, we present evidence in support of the hypothesis that systemically administered allogeneic MSCs neither accelerate the progression nor increase tumor malignancy of precancerous lesions. Moreover, we show that depending on the stage of the precancerous lesion and the dose of cells, the systemic administration of allogeneic MSCs precludes OSCC progression and tumor growth. To our knowledge, these observations are without precedent since the antitumor effect already described for systemically administered MSCs has been proven in animal models bearing preestablished tumors or receiving tumor cells together with the MSCs [23, 24].

The fact that systemically administered allogeneic MSCs do not aggravate the progression of precancerous lesions is a relevant safety outcome. Due to its simplicity and the ability of MSCs to home into injured tissues, intravenous injection is the preferred route in currently proposed MSC-based therapies. Most frequent malignancies arise from precancerous lesions, which are asymptomatic and underdiagnosed [25, 26]. Thus, there is a high probability that candidate patients for MSCbased therapies carry precancerous lesions, unnoticed by themselves and by clinicians. Here, we provide empirical evidence that this would not be a major health risk.

Regarding the beneficial effects of the systemic administration of MSCs, we observed a deterrence of OSCC progression when cells were injected at dysplasia or 

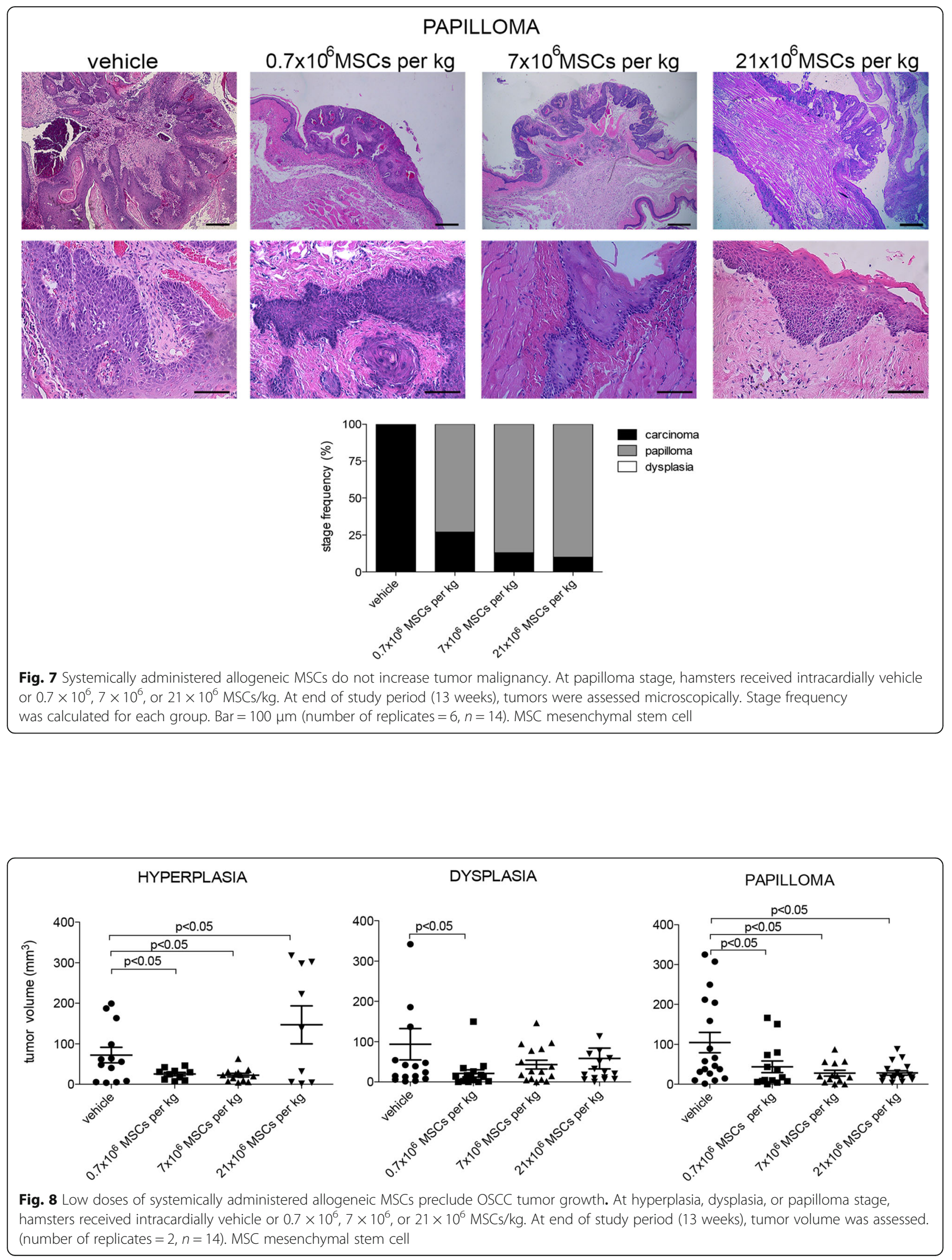

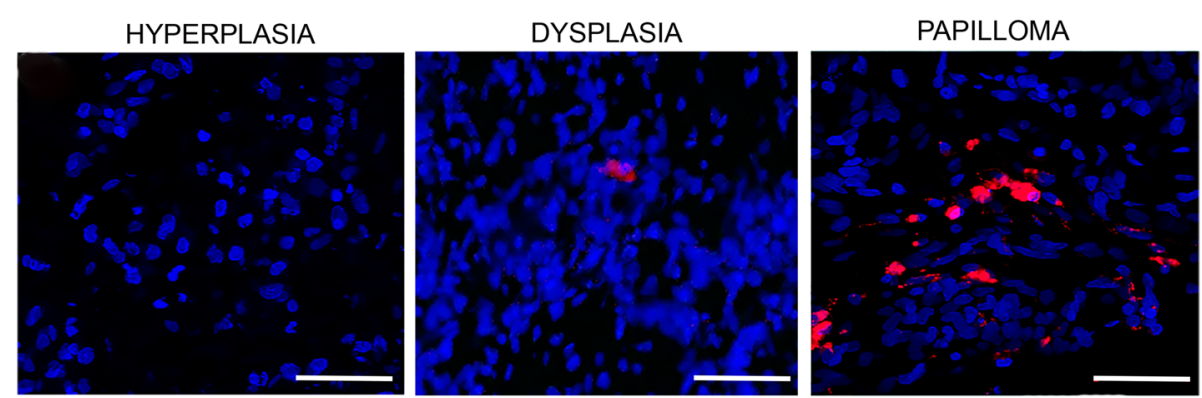

Fig. 9 Systemically administered allogeneic MSCs rarely home into precancerous lesions. At hyperplasia, dysplasia, or papilloma stage, hamsters received intracardially $21 \times 10^{6} \mathrm{CMTPX}$-labeled MSCs/kg. One day later, donor cells were sought in precancerous lesions. Bar $=50 \mu \mathrm{m}$ (number of replicates $=6, n=3$ )

papilloma stage but not at hyperplasia stage. Precancerous lesions at advanced stages presented chronic inflammation [27]. Thus, only at later stages might MSCs exert their immunomodulatory effect impairing cancer progression [28]. Since our study design lasted up to a fixed time point (13 weeks), we do not know whether this is a delay or suppression of OSCC progression. Prolonged follow-up is required to address this point.

The preclusion of OSCC tumor growth was observed irrespective of the stage of precancerous lesion but varied according to the number of cells injected. The dosedependent effect of MSCs has also been proven in other sceneries. In an ovine model of myocardial infarction it has been shown that the low doses $\left(25 \times 10^{6}\right.$ or $\left.75 \times 10^{6} \mathrm{MSCs}\right)$ but not the high ones $\left(225 \times 10^{6}\right.$ or $450 \times 10^{6}$ MSCs $)$ attenuated infarct expansion and preserved cardiac function [29]. When the safety and efficacy of $20 \times 10^{6}$, $100 \times 10^{6}$, or $200 \times 10^{6}$ MSCs were tested in patients with ischemic cardiomyopathy, the greatest effect in functional capacity was reached with the low dose of cells [30]. The improvement of fistula healing was observed when $30 \times 10^{6}$ MSCs were administered to patients with Crohn's disease, but not when the dose was $90 \times 10^{6}$ MSCs [31]. In all of these studies, the higher doses of MSCs were less effective or have no effect. In our study, the high dose of MSCs administered at hyperplasia stage resulted in an undesirable effect (bigger tumors). This could be explained by the fact that the administration of a large number of cells in a barely unhealthy animal might trigger an immune response against the donor cells, resulting in their deactivation or elimination, and/or might promote a long-term immunosuppression that facilitates posterior tumor growth [32].

As tumor growth restriction was not an expected outcome of the present work, our original study design did not consider exploration of the putative mechanisms behind it. Previously, we showed that local administration of allogeneic MSCs at dysplasia or papilloma stage precludes OSCC tumor growth (unpublished results, [19]). While at dysplasia stage MSCs impede mast cell infiltration and diminish tissue vascularization, at papilloma stage donor cells diminish proliferation, increase apoptosis, and reduce epithelial dedifferentiation. Thus, the cellular consequences of MSC administration vary according to the stage of precancerous lesion. Here, we observed that systemically administered allogeneic MSCs rarely home into precancerous lesions since we hypothesize that beneficial effects are due to systemic changes, as described for diseases like autoimmune encephalomyelitis or type 1 diabetes mellitus [10,33].

Although the limitation of our work is that results were obtained in an animal model for one type of cancer, the study represents a new biosafety insight for MSCbased cell therapy. Also, it is a first approach to the use of MSCs for the prevention of OSCC.

\section{Conclusions}

Systemically administered allogeneic MSCs do not aggravate the progression of precancerous lesions. Moreover, they preclude cancer progression and tumor growth.

\section{Additional file}

Additional file 1: Figure S1. Characterization of MSCs isolated from bone marrow of Syrian golden hamster. Immunophenotype (a) and differentiation potential (b). Dashed line, mean fluorescence intensity of isotype control. Bar = $100 \mu \mathrm{m}(n=4)$. (TIF $1623 \mathrm{~kb})$

\section{Abbreviations}

ANOVA: Analysis of variance; APC: Allophycocyanin; CMTPX: 5-(\{[4-

(Chloromethyl)phenyl]carbonyl\}amino)-2-(1,2,2,4,8,10,10,11-octamethyl-10,11dihydro-2H-pyrano[3,2-g:5,6-g']diquinolin-1-ium-6-yl)benzoate;

DAPI: 4',6-Diamidino-2-phenylindole dihydrochloride; DMBA: 7,12Dimethylbenz[a]anthracene; EDTA: Ethylenediaminetetraacetic acid; FITC: Fluorescein isothiocyanate; MEM: Minimum essential medium; MSC: Mesenchymal stem cell; OCT: Optimum cutting temperature embedding material; OSCC: Oral squamous cell carcinoma; SEM: Standard error of the mean

Funding

This work was supported by FONDECYT-Chile grant 1130760 (to PC). 


\section{Availability of data and materials}

The datasets used and/or analyzed during the current study are available from the corresponding author on reasonable request.

\section{Authors' contributions}

FB and AP contributed to acquisition, analysis, and interpretation of data. MA contributed to acquisition of data. IE contributed to analysis of data. PC contributed to conception and design of the study, and interpretation of data. All authors read and approved the final manuscript.

\section{Ethics approval and consent to participate}

This study was approved by the Ethic Committee of Facultad de Medicina Clinica Alemana-Universidad del Desarrollo (approval ID: 2011-14).

\section{Competing interests}

The authors declare that they have no competing interests.

\section{Publisher's Note}

Springer Nature remains neutral with regard to jurisdictional claims in published maps and institutional affiliations.

\section{Author details}

${ }^{1}$ Centro de Medicina Regenerativa, ICIM, Facultad de Medicina Clinica Alemana Universidad del Desarrollo, Av. Las Condes 12,438, Lo Barnechea, Santiago, Chile. ${ }^{2}$ Present Address: Laboratorio de Hormonas y Biologia del Cancer, Instituto de Medicina y Biologia Experimental de Cuyo (IMBECU), Mendoza, Argentina. ${ }^{3}$ Present Address: Unidad de Nefrologia, Instituto de Medicina, Facultad de Medicina, Universidad Austral de Chile, Valdivia, Chile. ${ }^{4}$ Present Address: Production Unity of Advanced Therapy, Fundacion Ofalmologica de Santander, Clinica Carlos Ardila Lulle (FOSCAL Internacional), Bucaramanga, Colombia.

Received: 17 February 2018 Revised: 16 April 2018

Accepted: 17 April 2018 Published online: 11 May 2018

\section{References}

1. Bourin P, Gadelorge M, Peyrafitte J-A, Fleury-Cappellesso S, Gomez M, Rage C, et al. Mesenchymal progenitor cells: tissue origin, isolation and culture. Transfus Med Hemother. 2008;35:160-7.

2. Conget PA, Minguell JJ. Phenotypical and functional properties of human bone marrow mesenchymal progenitor cells. J Cell Physiol. 1999;181:67-73.

3. Rasmusson I. Immune modulation by mesenchymal stem cells. Exp Cell Res. 2006:312:2169-79.

4. Ezquer F, Ezquer M, Simon V, Pardo F, Yañez A, Carpio D, et al. Endovenous administration of bone-marrow-derived multipotent mesenchymal stromal cells prevents renal failure in diabetic mice. Biol Blood Marrow Transplant. 2009;15:1354-65.

5. Hagenhoff A, Bruns CJ, Zhao Y, von Lüttichau I, Niess H, Spitzweg C, et al. Harnessing mesenchymal stem cell homing as an anticancer therapy. Expert Opin Biol Ther. 2016;16:1079-92.

6. Ezquer M, Ezquer F, Ricca M, Allers C, Conget P. Intravenous administration of multipotent stromal cells prevents the onset of non-alcoholic steatohepatitis in obese mice with metabolic syndrome. J Hepatol. 2011;55:1112-20.

7. Caplan Al, Dennis JE. Mesenchymal stem cells as trophic mediators. J Cell Biochem. 2006;98:1076-84.

8. Ball SG, Shuttleworth CA, Kielty CM. Mesenchymal stem cells and neovascularization: role of platelet-derived growth factor receptors. J Cell Mol Med. 2007:11:1012-30.

9. Valle-Prieto A, Conget PA. Human mesenchymal stem cells efficiently manage oxidative stress. Stem Cells Dev. 2010;19:1885-93.

10. Morando S, Vigo T, Esposito M, Casazza S, Novi G, Principato M, et al. The therapeutic effect of mesenchymal stem cell transplantation in experimental autoimmune encephalomyelitis is mediated by peripheral and central mechanisms. Stem Cell Res Ther. 2012;3:3.

11. Taylor PL, Barker RA, Blume KG, Cattaneo E, Colman A, Deng H, et al. Patients beware: commercialized stem cell treatments on the web. Cell Stem Cell. 2010;7:43-9.

12. Volarevic V, Markovic BS, Gazdic M, Volarevic A, Jovicic N, Arsenijevic N, et al. Ethical and safety issues of stem cell-based therapy. Int J Med Sci. 2018; 15:36-45.
13. Prockop DJ, Brenner M, Fibbe WE, Horwitz E, Le Blanc K, Phinney DG, et al Defining the risks of mesenchymal stromal cell therapy. Cytotherapy. 2010;12:576-8

14. Arango-Rodriguez ML, Ezquer F, Ezquer M, Conget P. Could cancer and infection be adverse effects of mesenchymal stromal cell therapy? World J Stem Cells. 2015;7:408-17.

15. Lalu MM, McIntyre L, Pugliese C, Fergusson D, Winston BW, Marshall JC, et al. Safety of cell therapy with mesenchymal stromal cells (SafeCell): a systematic review and meta-analysis of clinical trials. PLoS One. 2012;7:e47559.

16. Klopp AH, Gupta A, Spaeth E, Andreeff M, Marini F. Concise review: Dissecting a discrepancy in the literature: do mesenchymal stem cells support or suppress tumor growth? Stem Cells. 2011;29:11-9.

17. Young MRI. Redirecting the focus of cancer immunotherapy to premalignant conditions. Cancer Lett. 2017:391:83-8.

18. Schwartz J, Shklar G, Reid S, Trickier D. Prevention of experimental oral cancer by extracts of Spirulina-Dunaliella algae. Nutr Cancer. 1988;11:127-34.

19. Bruna F, Arango-Rodríguez M, Plaza A, Espinoza I, Conget P. The administration of multipotent stromal cells at precancerous stage precludes tumor growth and epithelial dedifferentiation of oral squamous cell carcinoma. Stem Cell Res. 2017;18:5-13.

20. Contador D, Ezquer F, Espinosa M, Arango-Rodriguez M, Puebla C, Sobrevia L, et al. Dexamethasone and rosiglitazone are sufficient and necessary for producing functional adipocytes from mesenchymal stem cells. Exp Biol Med. 2015;240:1235-46.

21. Cavalieri EL, Rogan EG. The approach to understanding aromatic hydrocarbon carcinogenesis. The central role of radical cations in metabolic activation. Pharmacol Ther. 1992;55:183-99.

22. Suzuki K, Sun R, Origuchi M, Kanehira M, Takahata T, Itoh J, et al. Mesenchymal stromal cells promote tumor growth through the enhancement of neovascularization. Mol Med. 2011;17:579-87.

23. Xia $L$, Peng $R$, Leng $W$, Jia $R$, Zeng $X$, Yang $X$, et al. TRAlL-expressing gingival-derived mesenchymal stem cells inhibit tumorigenesis of tongue squamous cell carcinoma. J Dent Res. 2015;94:219-28.

24. Sage EK, Kolluri KK, McNulty K, Lourenco SDS, Kalber TL, Ordidge KL, et al. Systemic but not topical TRAIL-expressing mesenchymal stem cells reduce tumour growth in malignant mesothelioma. Thorax. 2014;69:638-47.

25. Visvader JE, Lindeman GJ. Cancer stem cells in solid tumours: accumulating evidence and unresolved questions. Nat Rev Cancer. 2008:8:755-68.

26. Hegarty AM, Hunter KD. Oral malignancy and premalignancy. Br J Hosp Med. 2016:77:232-9.

27. Byun JS, Gardner K. Wounds that will not heal: pervasive cellular reprogramming in cancer. Am J Pathol. 2013;182:1055-64.

28. Spaeth E, Klopp A, Dembinski J, Andreeff M, Marini F. Inflammation and tumor microenvironments: defining the migratory itinerary of mesenchymal stem cells. Gene Ther. 2008;15:730-8.

29. Hamamoto H, Gorman JH, Ryan LP, Hinmon R, Martens TP, Schuster MD, et al. Allogeneic mesenchymal precursor cell therapy to limit remodeling after myocardial infarction: the effect of cell dosage. Ann Thorac Surg. 2009:87:794-801.

30. Hare JM, Fishman JE, Gerstenblith G, DiFede Velazquez DL, Zambrano JP, Suncion VY, et al. Comparison of allogeneic vs autologous bone marrowderived mesenchymal stem cells delivered by transendocardial injection in patients with ischemic cardiomyopathy. JAMA. 2012;308:2369-79.

31. Grégoire C, Lechanteur C, Briquet A, Baudoux É, Baron F, Louis E, et al. Review article: mesenchymal stromal cell therapy for inflammatory bowel diseases. Aliment Pharmacol Ther. 2017:45:205-21.

32. Djouad F, Bony C, Apparailly F, Louis-Plence P, Jorgense C, Noel D. Earlier onset of syngeneic tumors in the presence of mesenchymal stem cells. Transplantation. 2006;82:1060-6.

33. Ezquer F, Ezquer M, Contador D, Ricca M, Simon V, Conget $P$. The antidiabetic effect of mesenchymal stem cells is unrelated to their transdifferentiation potential but to their capability to restore Th1/Th2 balance and to modify the pancreatic microenvironment. Stem Cells. 2012;30:1664-74. 